\title{
Functional Importance of Sodium and Potassium in the Guinea Pig Cochlea Studied with Amiloride and Tetraethylammonium
}

\author{
Alec N. SalT* and Teruzo KonISHI \\ Laboratory of Environmental Biophysics, \\ National Institute of Environmental Health Sciences, \\ National Institutes of Health, \\ Research Triangle Park, N.C. 27709, U.S.A.
}

\begin{abstract}
The effects of amiloride on the cochlear responses in the guinea pig were compared with those produced by tetraethylammonium (TEA). Amiloride has been reported to reduce membrane permeability to sodium in a wide variety of ion-transporting epithelia. TEA has been documented to suppress the active potassium permeability increase during the repolarization phase of the action potential in mammalian excitable cells, and to reduce the resting potassium conductance in mammalian smooth muscle cells. Perilymphatic perfusion of $10^{-3} \mathrm{M}$ amiloride or intravenous injection at a dose of $20 \mathrm{mg} / \mathrm{kg}$ suppressed the whole nerve action potential (AP) of the cochlea but did not significantly affect the cochlear microphonics (CM) or endocochlear potential (EP). Application of amiloride to endolymph by iontophoretic or perfusion techniques also produced no significant changes of $\mathrm{CM}$ and EP when compared with appropriate control procedures. Perilymphatic perfusion of $10^{-2} \mathrm{M}$ TEA did not suppress CM or EP but the AP was reduced. Iontophoretic application of TEA to the endolymph caused a marked suppression of CM while the EP was significantly increased. The effects of endolymphatic TEA application are consistent with the concept that the normal EP recorded from scala media is the algebraic sum of a positive electrogenic potential and a negative diffusion potential, the latter component being sensitive to potassium permeability changes of the endolymph-perilymph barrier. Maintenance of normal cochlear microphonics also appears dependent upon the maintenance of normal potassium permeability properties of the endolymph-perilymph barrier. The functional importance of normal sodium permeability properties appears less certain.

Key Words: sodium, potassium, cochlea, permeability.
\end{abstract}

Received for publication July 2, 1981

* Present address: Auditory Evoked Potentials Team, Institute of Sound and Vibration Research, University of Southampton, Southampton, S09 5NH U.K.

小西輝三 
The maintenance of the normal electrical polarization and ionic composition of the cochlear endolymph depends not only upon the active ionic transport mechanisms of stria vascularis, but also on the permeability properties of those cells which represent the endolymph-perilymph barrier (JAHNKE, 1975; SMITH, 1978). Studies by Konishi et al. (1979) and Konishi and SALt (1980) have indicated that changes in the permeability of the endolymph-perilymph barrier to potassium ions may represent an important factor in the hearing loss produced by intermediate levels of noise or treatment with ototoxic antibiotics. BOSHER (1980) has also reported that one effect of ethacrynic acid on the cochlea is to decrease cation permeabilities of the endolymph system, primarily with respect to potassium ions.

The present study has used amiloride and tetraethylammonium in an attempt to assess the relative importance of sodium and potassium ion movements to cochlear function. Amiloride is known as a potassium sparing diuretic that acts primarily upon the distal tubule in the mammalian kidney (DUARTE et al., 1971). Following studies in the toad bladder (BENTLEY, 1968; Sudou and HoSHI, 1977), the renal tubule (STONER et al., 1974), and the submaxillary gland (SCHNEYER, 1970), there is a concensus that the primary action of amiloride on ion transporting epithelia is to reduce the permeability of the luminal cell membrane to sodium ions. Tetraethylammonium (TEA) has been demonstrated to suppress the increase of potassium permeability during repolarization of the excitable cell membrane after an action potential (FATT and KATZ, 1953) and to reduce the resting potassium conductance in smooth muscle cells (ITO et al., 1970; HARDER and SPERELAKIS, 1979).

The present study has compared the effects of amiloride or TEA applied to the endolymphatic or perilymphatic scalae on the tone-induced cochlear potentials and on endocochlear potential (EP). Preliminary findings were presented to the Acoustical Society of America (SALT and KonISHI, 1979).

\section{METHODS}

Guinea pigs weighing 300-500 g were anesthetized with sodium pentobarbital $(30-35 \mathrm{mg} / \mathrm{kg}$ ) and differential electrodes were positioned in the perilymphatic scalae of the cochlea to record cochlear microphonics (CM) and action potentials (AP). Unless otherwise specified, test stimuli were $6 \mathrm{kHz}$ tone bursts presented at $72 \mathrm{~dB}$ SPL. EP was recorded from the basal turn of scala media with glass electrodes inserted through the spiral ligament. During recording, animals were immobilized with gallamine triethiodide and were artificially respired. Rectal temperature was maintained at $39^{\circ} \mathrm{C}$ with a thermistor controlled heating pad.

Amiloride was applied to the cochlea by the following methods: i) perilymphatic perfusion, ii) iontophoretic injection into endolymph, iii) intravenous injection, iv) endolymphatic perfusion. TEA was applied by the first two methods only. 
The technique for the perfusion of the perilymphatic space has been fully described previously (KONISHI and KELSEY, 1968). Briefly, perfusate was introduced into the basal turn of scala tympani at a rate of $2 \mu \mathrm{l} / \mathrm{min}$. The duration of perfusion was $40 \mathrm{~min}$. Fluid was allowed to escape from a hole in the basal turn of scala vestibuli and was removed from the middle ear with fine cotton wicks. Perfusion holes were positioned basally to the differential recording electrode located in the same scala. For perfusion, amiloride $\left(10^{-3} \mathrm{M}\right)$ or TEA $\left(10^{-2} \mathrm{M}\right)$ was dissolved in a Ringer's solution, the composition of which is described elsewhere (KoNISHI and KeLSEY, 1973).

The application of drugs to the endolymphatic space by iontophoresis utilized single barreled glass electrodes with their tips broken to $2-3 \mu \mathrm{m}$. Electrodes were filled with $160 \mathrm{~mm} \mathrm{KCl}, 160 \mathrm{~mm} \mathrm{KCl}$ saturated with amiloride (approx. $5 \mathrm{~mm}$ ), or $160 \mathrm{~mm}$ tetraethylammonium chloride. They were inserted into scala media and EP monitored until a stable level had been achieved. A pulsed current of $3 \times 10^{-7} \mathrm{~A}(0.5 \mathrm{sec}$ pulse width, $1 / \mathrm{sec})$ was then passed to eject either $\mathrm{K}^{+}$ions or the drugs, which are present as cations in aqueous solution. The duration of iontophoresis was $20 \mathrm{~min}$. EP was monitored from the electrode at intervals, during which time the iontophoresis current was briefly interrupted. In vitro testing determined that the current levels used in the present study did not polarize the electrode and hence did not generate artifactual changes in EP.

Amiloride was also applied to the cochlea by intravenous injection into the left jugular vein or by perfusion of the endolymphatic space. Details of endolymphatic perfusion are described elsewhere (KonISHI, 1979). A solution of $160 \mathrm{~mm} \mathrm{KCl}$ (control) or $10^{-5} \mathrm{M}$ amiloride dissolved in $160 \mathrm{mM} \mathrm{KCl}$ was injected into the basal turn of scala media at a rate such that approximately $1 \mu \mathrm{l}$ was injected during $20 \mathrm{~min}$. Perfusate was allowed to escape from the cochlear apex by rupturing Reissner's membrane in the fourth turn. CM and EP were recorded from differential electrodes located in the second cochlear turn. In these experiments test stimuli were $1 \mathrm{kHz}$ tone bursts presented at $66 \mathrm{~dB}$ SPL.

Significance of results was tested using Dunnett's modified $t$-test for the comparison of multiple treatment groups with 1 control group (STEEL and TORRIE, 1960).

\section{RESULTS}

\section{1) Perilymphatic/Intravenous application}

When the perilymphatic space was perfused at $2 \mu \mathrm{l} / \mathrm{min}$ with Ringer's solution (control procedure) there were minor changes of CM, AP, and EP. The average response changes recorded during control perfusions in six guinea pigs are summarized in the upper panel of Fig. 1. After 40 min perfusion, CM was slightly suppressed, falling by a mean value of $9.3 \%$ relative to the pre-perfusion response level. Both AP and EP tended to increase a little during the perfusion period, 


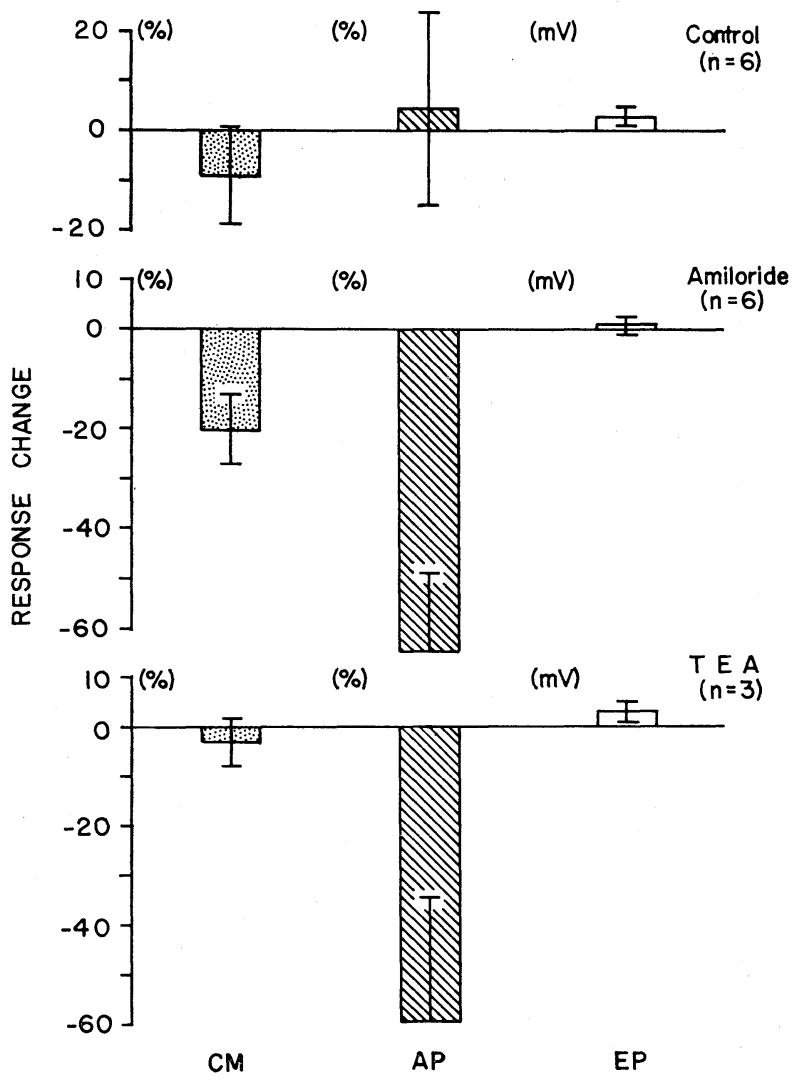

Fig. 1. The mean changes of cochlear responses produced by $40 \mathrm{~min}$ perfusion of the perilymphatic space with Ringer's solution or solution containing $10^{-3} \mathrm{M}$ amiloride or $10^{-2} \mathrm{M}$ TEA. Cochlear microphonics (CM) and action potentials (AP) were recorded in response to $6 \mathrm{kHz}$ tone bursts at $72 \mathrm{~dB}$ SPL. Changes in CM and AP are presented as the percentage change in response measured at $40 \mathrm{~min}$ relative to the pre-perfusion value. Endocochlear potential (EP) changes are the difference $(\mathrm{mV})$ between the EP recorded at $40 \mathrm{~min}$ and the pre-perfusion value. Bars indicate the standard deviation of the mean value.

although changes in AP were variable. The mean response increases for AP and EP were $4.0 \%$ and $2.6 \mathrm{mV}$ respectively. The changes resulting from perfusion with $10^{-3} \mathrm{M}$ amiloride or $10^{-2} \mathrm{M}$ TEA solutions in six and three guinea pigs respectively, are summarized in the center and lower panels of Fig. 1. In both cases, after $40 \mathrm{~min}$ perfusion the CM was suppressed, but not to a significantly greater degree than produced by control perfusion. In contrast, the AP showed considerable suppression after perfusion with amiloride or TEA, the mean suppressions being 65.1 and $60.0 \%$ respectively. In both cases the changes were significantly greater than those produced by control perfusion $(p<0.01$, Dunnett's 


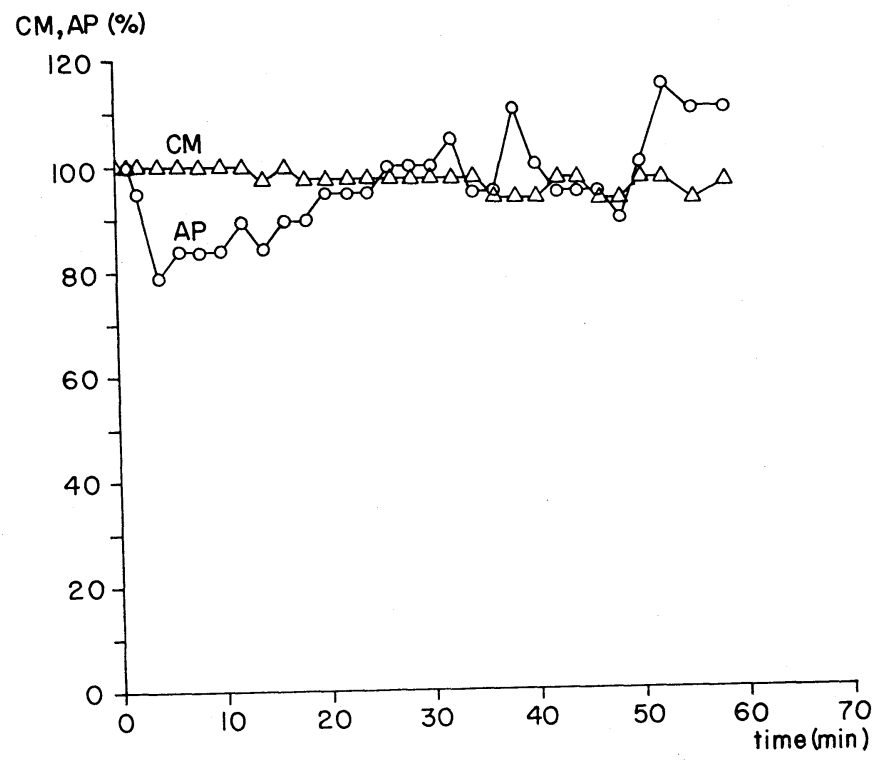

Fig. 2. An example of the variation of cochlear microphonics (CM) and action potentials (AP) with time after an intravenous injection of $20 \mathrm{mg} / \mathrm{kg}$ amiloride. CM and AP were recorded from the basal turn in response to $6 \mathrm{kHz}$ tone bursts at $72 \mathrm{~dB}$ SPL. Data were taken from a single guinea pig.

modified $t$-test). Both amiloride and TEA perfusion increased EP slightly but the increases were not significant compared with control perfusions.

The changes of CM and AP with time after intravenous injection of amiloride at a dose of $20 \mathrm{mg} / \mathrm{kg}$ are illustrated in Fig. 2. Immediately after injection AP exhibited a transient depression to approximately $80 \%$ of the pre-injection value, but within $30 \mathrm{~min}$ it had fully recovered. CM showed no systematic changes during the $60 \mathrm{~min}$ period following injection.

\section{2) Endolymphatic application}

Figure 3 illustrates the changes of CM, AP, and EP with time during $20 \mathrm{~min}$ iontophoresis from an electrode containing $160 \mathrm{mM} \mathrm{KCl}$. During the period of iontophoresis CM was slightly suppressed while AP and EP increased in value. A similar pattern of response changes was observed when the iontophoretic electrode contained $160 \mathrm{mM} \mathrm{KCl}$ saturated with amiloride. Changes of CM, AP, and EP during amiloride iontophoresis are illustrated in Fig. 4. Once again, $\mathrm{CM}$ was suppressed a little while AP and EP were slightly elevated at the end of the perfusion period. In contrast, much greater response changes were produced by the iontophoretic injection of TEA into the endolymph, as illustrated in Fig. 5. During the period of iontophoresis CM was suppressed to less than $50 \%$ of the 


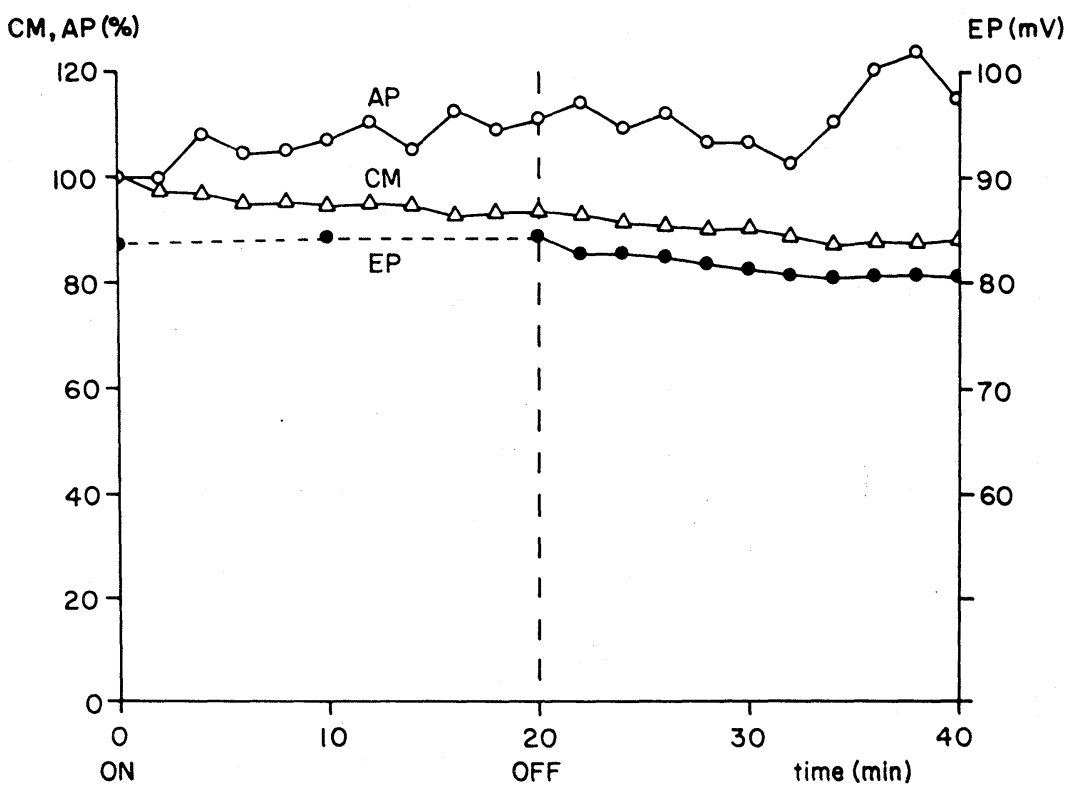

Fig. 3. Variation of cochlear microphonics (CM) action potentials (AP) and endocochlear potential (EP) with time during iontophoretic injection of potassium into the endolymph of a single guinea pig (control procedure). A pulsed current of $3 \times 10^{-7} \mathrm{~A}$ ejected ions from an electrode containing $160 \mathrm{mM} \mathrm{KCl}$. $\mathrm{CM}$ and $\mathrm{AP}$ have been normalized with respect to their pre-treatment values.

pre-treatment level. At the same time, EP showed a marked enhancement, increasing in value by approximately $10 \mathrm{mV}$ during the $20 \mathrm{~min}$ period of iontophoresis. In similarity with the control procedure, AP was increased by TEA treatment. In the $20 \mathrm{~min}$ period following iontophoresis $\mathrm{CM}$ continued to decline while AP and EP appeared stable at their increased levels. The mean response changes during $20 \mathrm{~min}$ control, amiloride or TEA iontophoresis are summarized in Fig. 6 . The changes generated by amiloride treatment were not significantly different from those produced by control injection. TEA produced a mean $\mathrm{CM}$ suppression of $36.0 \%$ during 20 min iontophoresis which was significantly greater than that produced by the control procedure $(p<0.01$, Dunnett's $t$-test). The mean increase of EP by $9.5 \mathrm{mV}$ was also highly significant compared with the control experiment ( $p<0.01$, Dunnett's $t$-test). The AP response was not changed significantly more by TEA than by control iontophoresis.

Although it was felt that a significant amount of amiloride was injected by the iontophoretic technique used, the limited solubility of amiloride restricted the amount that could be administered by this method. Larger doses were therefore applied to endolymph by injecting them into the basal turn of scala media by a direct perfusion technique. Since the basal turn responses were very sensitive 


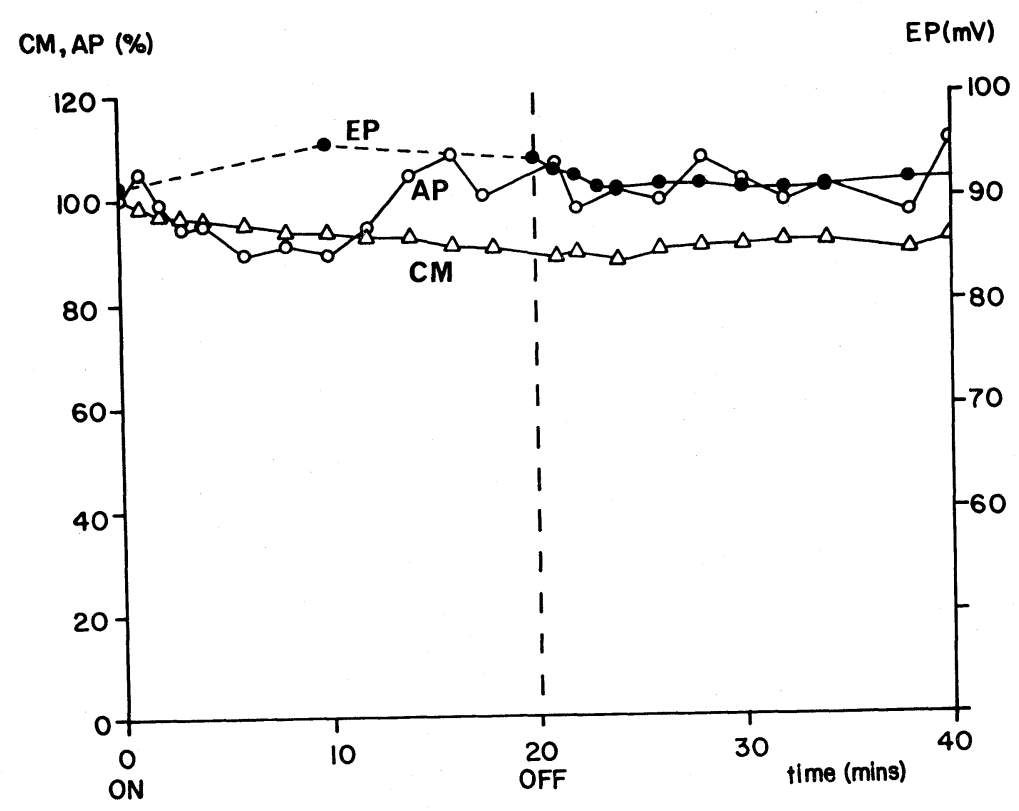

Fig. 4. Variation of cochlear microphonics (CM), action potentials (AP), and endocochlear potential (EP) with time during iontophoretic application of amiloride into the endolymph of a single guinea pig. The electrode contained $160 \mathrm{mM} \mathrm{KCl}$ saturated with amiloride. The pulsed injection current was $3 \times 10^{-7} \mathrm{~A}$. CM and AP were normalized with respect to their pre-treatment values.

to $160 \mathrm{mM} \mathrm{KCl}$ (control) injections, response changes were monitored from the second turn of the cochlea. In this series of experiments a $1 \mathrm{kHz}$ tone burst at $66 \mathrm{~dB}$ SPL was used as a stimulus to elicit CM. The upper panel of Fig. 7 illustrates the changes of $\mathrm{CM}$ and EP in the second turn during a control injection of $\mathrm{KCl}$ into the basal turn. Commencing almost immediately both $\mathrm{CM}$ and EP declined slowly with time. After the injection was halted CM recovered to some extent but EP remained suppressed. Generally similar changes were observed when $160 \mathrm{mM} \mathrm{KCl}$ containing $10^{-5} \mathrm{M}$ amiloride was injected into the basal turn. In this case the changes during injection were quantitatively similar to those observed in control experiments. Response changes after injection were also similar although the time course of $\mathrm{CM}$ recovery was variable in both control and amiloride treated animals. Thus it appears that even at an amiloride dose as high as $10^{-5} \mathrm{M}$, cochlear response changes were no greater than those produced by control procedures.

\section{DISCUSSION}

It has been widely reported that amiloride $\left(10^{-7}\right.$ to $\left.10^{-5} \mathrm{M}\right)$ applied to the 


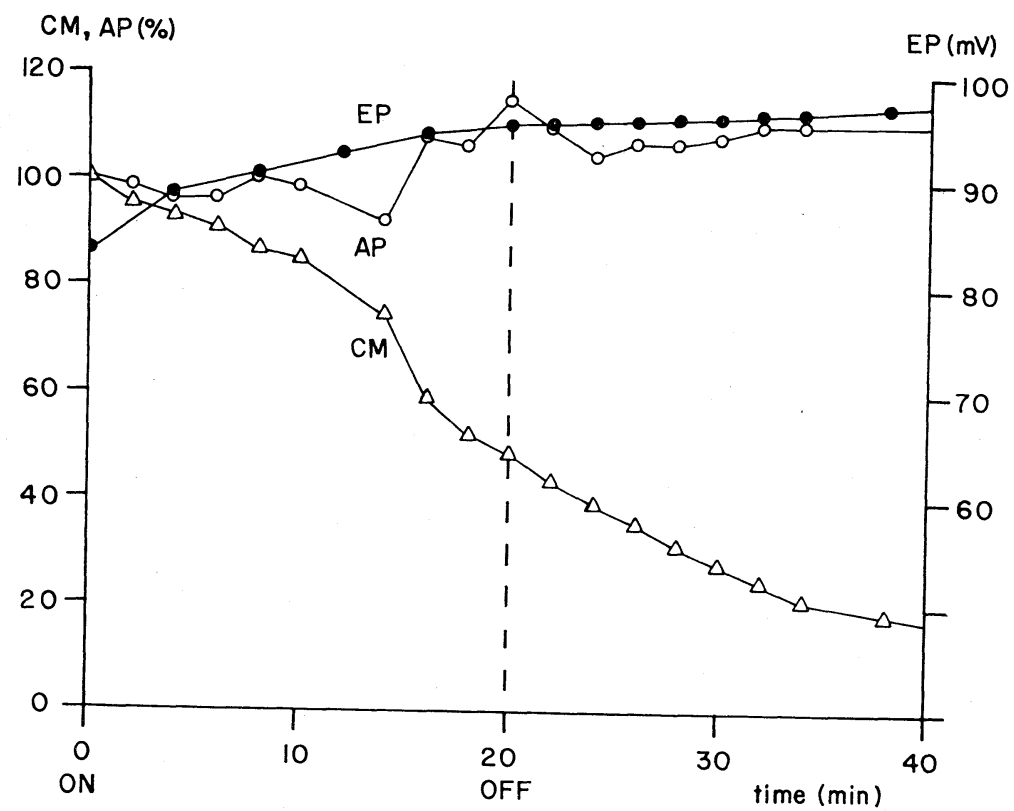

Fig. 5. Variation of cochlear microphonics (CM), action potentials (AP), and endocochlear potential (EP) with time during iontophoretic injection of TEA into the endolymph of a single guinea pig. The electrode contained $160 \mathrm{~mm}$ tetraethylammonium chloride which was ejected by a pulsed current of $3 \times 10^{-7} \mathrm{~A}$. CM and AP were normalized with respect to their pre-treatment values.

luminal surface of some epithelia produces a decrease or reversal of transepithelial potential difference, an increase in epithelium resistance and disturbances of ion fluxes (Bentley, 1968; SCHNEyer, 1970; Stoner et al., 1974). It is postulated that many of these changes arise either directly or indirectly (via potential difference changes) from a decrease in the sodium permeability of the mucosal membrane. In contrast, the application of amiloride either to the serosal surface (BENTLEY, 1968; STONER et al., 1974) or by systemic injection (SCHNEYER, 1970) was reported to produce negligible changes in epithelium properties. In the present study the failure of amiloride to affect CM or EP when applied to the perilymph or injected intravenously appears to be compatible with the data reported in other tissues. These data suggest that amiloride does not have access to its site of action by these routes. On the other hand, the application of amiloride to the endolymph would be expected to give amiloride access to the apical membrane of the hair cells (which may be analogous to the luminal application in other epithelia). When applied to endolymph in doses up to $10^{-5} \mathrm{M}$ (by injection) amiloride failed to influence CM or EP. A possibility remains that sodium permeability of the sensory epithelium of the cochlea is unaffected by amiloride. However, if amiloride does indeed reduce the sodium permeability, this does not 


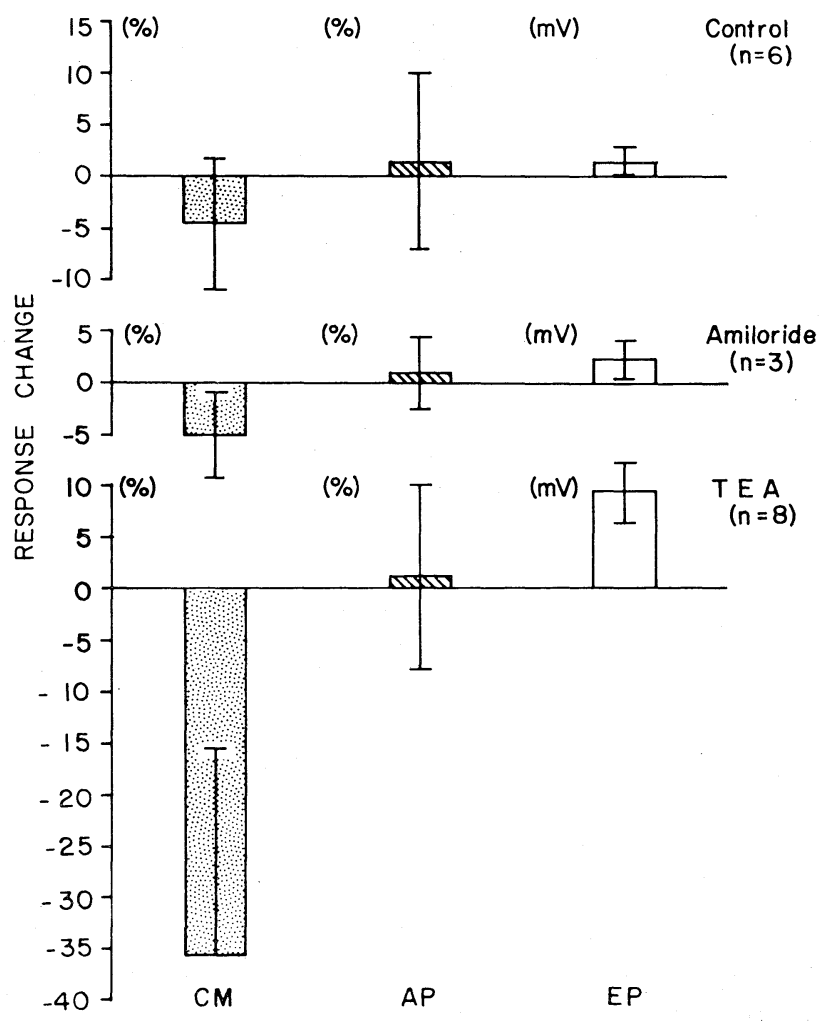

Fig. 6. The mean changes in cochlear responses produced by control, amiloride, and TEA iontophoresis into endolymph. Cochlear microphonics (CM) and action potentials (AP) were recorded in response to $6 \mathrm{kHz}$ tone bursts at $72 \mathrm{~dB}$ SPL and are expressed as the percentage change after $20 \mathrm{~min}$ iontophoresis, relative to the pre-treatment value. Endocochlear potential $(\mathrm{EP})$ changes are the difference $(\mathrm{mV})$ between the EP recorded after 20 min iontophoresis relative to the pre-treatment value. Bars indicate the standard deviation of the mean value.

seem to have any immediate effect on cochlear function. It should be noted that in other ion-transporting epithelia, the mucosal cell membrane, at which amiloride is thought to act, is bathed on the extracellular side by medium containing a moderate or high sodium concentration. The unique situation in the endolymphatic system, where this membrane is bathed in potassium-rich medium with a $\mathrm{Na}^{+}$concentration of approximately $1 \mathrm{~mm}$ (KoNISHI et al., 1979), may account for the lack of effect of amiloride as the rate of efflux of sodium from endolymph must be very small under normal physiological conditions. Thus it is probable that a change in the sodium permeability properties of the membranes bounding scala media may not have any immediate effect on cochlear function. The failure of amiloride to alter cochlear potentials indicates that the potential ototoxicity 


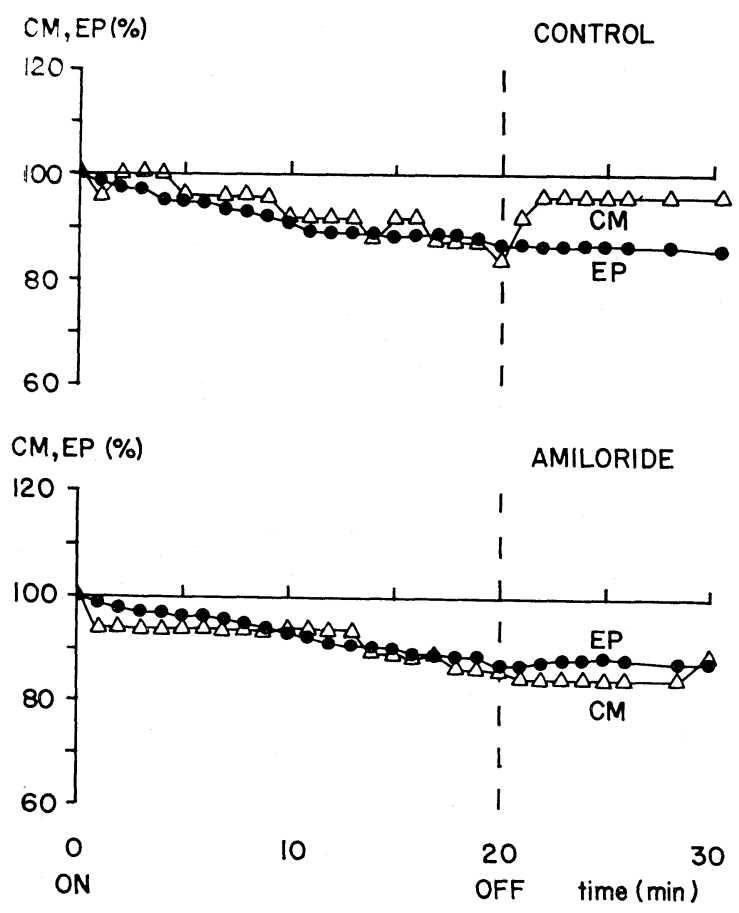

Fig. 7. Changes of cochlear microphonics (CM) and endocochlear potential (EP) during $20 \mathrm{~min}$ injection of $160 \mathrm{mM} \mathrm{KCl}$ (Control) or $160 \mathrm{mM} \mathrm{KCl}+10^{-5} \mathrm{M}$ amiloride into scala media of the basal turn. Responses were monitored in the second turn, the CM being elicited by $1 \mathrm{kHz}$ tone bursts at $66 \mathrm{~dB}$ SPL. CM and EP have been normalized with respect to their pre-injection values.

of amiloride may be negligible. This contrasts with the marked ototoxicity shown by some "loop" diuretics, such as ethacrynic acid which may in part be related to changes in the permeability of the endolymph-perilymph barrier (BosHeR, 1980).

TEA applied to the perilymphatic scalae suppressed the AP response, presumably by disturbing the mechanism of repolarization of the afferent neurons. $\mathrm{CM}$ and EP were not affected by perilymphatic application, indicating that those regions accessible to TEA are either unaffected or do not contribute to CM and EP generation. The iontophoretic injection of TEA into endolymph produced a long lasting suppression of $\mathrm{CM}$ and a considerable increase in EP. The observed EP increase provides support for the hypothesis that the measured EP in the normal cochlea is the sum of an active positive component and a passive negative diffusion potential, primarily generated by the diffusion of potassium ions. In terms of this model, TEA, by decreasing potassium permeability of the endolymph-perilymph barrier, would decrease the negative diffusion potential 
component of EP and cause the measured EP to move in a positive direction. Alternate models have been proposed (AsAKuma et al., 1979) in which it is argued that the negative EP does not exist in the normal cochlea and is only generated by the hair cells in the anoxic condition. Under this model, the increase of EP with TEA treatment is difficult to explain since no stimulation of active ion transport mechanisms by TEA has been reported. The suppression of CM by TEA supports our previous studies (KoNISHI et al., 1979; KONISHI and SALT, 1980) which indicate that maintenance of normal potassium permeability between endolymph and perilymph is essential for normal cochlear function. Thus, the concept described by KATSUKI et al. (1966) and developed by SELLICK and JoHnSTONE (1975), that the CM may be generated by the modulation of a current of potassium ions, is supported by our data. The failure of TEA to suppress AP when applied to the endolymph cannot be fully explained but may be partially a consequence of the experimental conditions. The application of TEA and the recording of EP and CM all involved a very localized region of the cochlea. In contrast, the AP response, which unlike the CM was not recorded differentially, could include the contribution of more distant elements which were stimulated by the $6 \mathrm{kHz}$ tone at $72 \mathrm{~dB}$ SPL but were too remote to be affected by the TEA. However, if this were the case and those elements near the site of TEA application were indeed suppressed, a small reduction of AP may have been expected. It is therefore possible that the neural elements did remain functional even when the $\mathrm{CM}$ was reduced, a phenomenon which may merit further investigation.

In a previous study, KATSUKI et al. (1966) injected TEA into the endolymph by iontophoresis and reported a considerable decrease in both CM and EP. The difference between these findings and our own with respect to the EP changes are explained by a difference in the doses of TEA used. Katsuki et al. used an injection current of $8 \times 10^{-6} \mathrm{~A}$, which is more than ten times greater than the current used in the present study. We have ascertained that when injection current levels exceeding $1 \times 10^{-6} \mathrm{~A}$ are used the EP initially becomes elevated but subsequently falls to a lower level as the amount of TEA in the endolymph increases. Thus changes in EP appear to be dose-related, with moderate TEA doses giving EP enhancement and high TEA doses resulting in EP depression.

The authors wish to thank Dr. Y. Katsuki, National Center for Biological Sciences and Dr. K. Yanagisawa, Department of Physiology, Tsurumi University School of Dental Medicine for their valuable suggestions concerning action of tetraethylammonium.

\section{REFERENCES}

Asakuma, S., Lowry, L. D., and SNow, J. B., Jr. (1979) Effect of kanamycin sulfate on the endocochlear dc potential of guinea pigs. Arch. Otolaryngol., 105: 145-148.

BeNTLEY, P. J. (1968) Amiloride: A potent inhibitor of sodium transport across the toad bladder. J. Physiol. (Lond.), 195: 317-330.

BosHer, S. K. (1980) The nature of the ototoxic actions of ethacrynic acid upon the mammalian

Vol. 32, No. 2, 1982 
endolymph system. Acta Otolaryngol., 89: 407-418.

Duarte, C. G., Сhомety, F., and Giebisch, G. (1971) Effect of amiloride, ouabain, and furosemide on distal tubular function in the rat. Am. J. Physiol., 221: 632-639.

Fatt, P. and Katz, B. (1953) The electrical properties of crustacean fibers. J. Physiol. (Lond.), 120: 171-204.

Harder, D. R. and Sperelakis, N. (1979) Action potentials induced in guinea pig arterial smooth muscle by tetraethylammonium. Am. J. Physiol., 237: C75-C80.

Ito, Y. H., KuRiYama, H., and SaKamoto, Y. (1970) Effects of tetraethylammonium chloride on the membrane activity of guinea pig stomach muscle. J. Physiol. (Lond.), 246: 445-460.

JAHNKE, K. (1975) The fine structure of freeze-fractured intercellular junctions in the guinea pig inner ear. Acta Otolaryngol., 336: 1-40.

KatSUKI, Y., YANAGISAWA, K., and KANZAKI, J. (1966) Tetraethylammonium and tetrodotoxin: Effects on cochlear potentials. Science, 151: 1544-1545.

Konishi, T. (1979) Effects of local application of ototoxic antibiotics on cochlear potentials in guinea pigs. Acta Otolaryngol., 88: 41-46.

Konishi, T. and Kelsey, E. (1968) Effect of sodium deficiency on cochlear potentials. $J$. Acoust. Soc. Am., 43: 462-470.

Konishi, T. and KelSey, E. (1973) Effect of potassium deficiency on the cochlear potentials and cation contents of the endolymph. Acta Otolaryngol., 76: 410-418.

Konishi, T. and SALt, A. N. (1980) Permeability to potassium of the endolymph-perilymph barrier and its possible relation to hair cell function. Exp. Brain Res., 40: 457-463.

Konishi, T., Salt, A. N., and Hamrick, P. E. (1979) Effects of exposure to noise on ion movement in guinea pig cochlea. Hearing Res., 1: 325-342.

SALt, A. N. and KonISHI, T. (1979) The role of potassium and sodium in cochlear transduction: A study with amiloride and tetraethylammonium. J. Acoust. Soc. Am., 66: S47.

Sellick, P. M. and Johnstone, B. M. (1975) Production and role of inner ear fluid. Prog. Neurobiol., 5: 337-362.

SCHNEYER, L. H. (1970) Amiloride inhibition of ion transport in perfused excretory duct of rat submaxillary gland. Am. J. Physiol., 219: 1050-1055.

Sмith, C. A. (1978) Structure of the cochlear duct. In: Evoked Electrical Activity in the Auditory Nervous System, ed. by Naunton, R. F. and Fernandez, C. Academic Press, New York, pp. 3-19.

Steel, R. G. D. and Torrie, J. H. (1960) Principles and Procedures of Statistics, McGraw Hill, New York, pp. 111-115.

Stoner, L. C., Burg, M. B., and ORLoff, J. (1974) Ion transport in cortical collecting tubule: Effect of amiloride. Am. J. Physiol., 227: 453-459.

Sudou, K. and Hoshi, T. (1977) Mode of action of amiloride in toad urinary bladder. $J$. Membr. Biol., 32: 115-132. 